\title{
Using Toe Framework to Analyze Factors Influencing Social Media Usage by Micro, Small and Medium Enterprises
}

\author{
Muhammad Ardiansyahe, ${ }^{\mathrm{a}, 1, *}$, Peni Sawitri ${ }^{\mathrm{b}, 2}$, Sanusi ${ }^{\mathrm{c}, 3}$ \\ ${ }^{a}$ Universitas Teuku Umar, Meulaboh-Tapaktuan Street, Aceh Barat, 23615, Indonesia \\ ${ }^{b}$ Gunadarma University, Depok, Jawa Barat, 16424, Indonesia(9pt) \\ ${ }^{c}$ Universitas Teuku Umar, Meulaboh-Tapaktuan Street, Aceh Barat, 23615, Indonesia \\ ${ }^{1}$ m.ardiansyah@utu.ac.id*; ${ }^{2}$ peni@staff.gunadarma.ac.id; ${ }^{3}$ sanusi@utu.ac.id
}

\section{ARTICLE INFO}

Article history:

Accepted

\section{ABSTRACT}

This study aims to evaluate the factors that influence the use of social media in micro, small and medium enterprises. By using a mixed qualitative and quantitative approach, the study examines the influence of factors based on the TOE (Technology-OrganizationEnvironment) Framework theory. The data collection process was carried out by means of interviews and questionnaires distributed online. From the quantitative analysis conducted on 100 samples using multiple linear regression techniques, it is known simultaneously that the factors in the context of the TOE Framework have a significant effect on the use of social media in MSMEs. In the context of technology, the factors that have a significant effect on the use of social media are the interactivity of social media and the suitability of the technology that has been previously owned. Data analysis was carried out using SPSS 25 . The results of the study concluded that the suitability factor, inter-activity and entrepreneurial orientation had a significant effect on the use of social media in MSMEs.

\section{Introduction}

Social media is one of the contributors to the growth of online businesses in Indonesia. Especially those that provide a platform that allows users to exchange images, text, videos and even hyperlinks to connect to other websites. Even today, Facebook and Instagram as social media providers offer customized advertising services that allow businesses to target audiences with various demographic criteria. States that online businesses can target 130 million users with Facebook ads and 62 million users with Instagram Ads. The data is measured based on the number of active users each month [1].

In the context of MSMEs states that according to research conducted by taking a sample of 205 MSMEs in Oman, around $66 \%$ of them use at least one social media, which indicates that social media is widely accepted by MSMEs in Oman for various reasons [2]. which underlies the use of which has a significant influence on business performance. In addition, two thirds of the $34 \%$ who do not use social media stated that they plan to adopt use in the future. Meanwhile in Indonesia, based on research conducted by on 38 MSMEs concluded that almost all MSMEs studied have used social media of different types, and Facebook is the most widely used social media compared to other social media.

The analysis in this paper will be based on the theory of the Technology-OrganizationEnvironmental (TOE) Framework. The TOE Framework was chosen because based on research conducted by concluded that the TOE Framework is one of the theories that is often used in studying the adoption of a technology in organizations [3]. 


\section{Research Method}

The population used in this study is MSME businesses located in Jakarta, West Java, Banten and surrounding areas that have used social media in their business. The evaluated factors include factors in the context of technology, organization, and environment based on the Technological-Organizational-Environmental (TOE) Framework. The sample selection in this study used purposive sampling method. Purposive sampling is a non-probability method where potential participants are selected based on "specific goals" because of their qualities in order to produce the best knowledge about the problems studied [2]. The characteristics that must be possessed by respondents are owners, managers or admins who know the level of use of social media in MSMEs.

This study uses sequential mixed-methods in the form of qualitative and quantitative. Sequential mixed-methods is a design in which at least two stages of research are carried out sequentially. This method was chosen because it is believed to provide deeper and broader knowledge about research. Qualitative methods are expected to provide in-depth knowledge of the problem under study, then quantitative methods are used to gain broader knowledge.

Data analysis in this study was carried out using SPSS with multiple linear regression techniques. Regression is one of the most efficient statistical tools used to investigate the relationship between a given number of variables. The wide range of application and flexibility of this technique is associated with the fact that the regression technique provides a simple method for connecting the relationships between variables, understanding the impact of the independent variable, one or more dependent variables [4]. With the help of a software package such as SPSS, it is hoped that the regression analysis process to conclude the relationship between variables becomes easier.

\section{Results and Discussion}

\subsection{Qualitative Analysis Results}

The results of the interviews conducted provide important information regarding the use of social media for MSMEs in the city of Jakarta and its surroundings. Among the information obtained from interviews are the types of social media that are widely used by SMEs today, namely Instagram and Facebook. Through interviews conducted, it was also known that MSMEs use social media for various purposes ranging from promotion, brand building, customer service activities, market and competitor research, getting referrals, and placing advertisements.

The study also found the influence of the context of technology, organization, and environment on the use of social media in MSMEs. Various factors originating from the TOE Framework concept are known to influence the use of social media in MSMEs. From the technology context, factors such as suitability, interactivity, trustworthiness, and cost effectiveness are known to have an important influence on the use of social media in MSMEs. These results are in accordance with qualitative research conducted by [2], [5].

From the organizational context, from the interviews conducted, it is known that management support and entrepreneurial orientation affect MSMEs in using social media. These results are in line with previous research conducted by [2]. Meanwhile, from the environmental context, from interviews conducted, it is known that the institutional pressure factors received by MSMEs have an influence on the use of social media. These results are in line with research conducted by [5].

\subsection{Validity Testing}

The validity test aims to determine the extent to which the instrument used in the study is able to measure what it wants to measure. The validity test is an important element in concluding the quality of the data produced, as well as the value of the research as a whole. In this study, the validity test was carried out using the bivariate correlation Pearson moment method on IBM SPSS 25 software. According to the Pearson moment technique, an instrument is valid if it has an $\mathrm{R}$ value $>\mathrm{R}$ table. By using a significance of 0.05 , all instruments in the study met the requirements for $\mathrm{R}$ value greater than $R$ table (0.195) and could be declared valid. 


\subsection{Reliability Testing}

Reliability measures the extent to which a survey will produce similar results under different circumstances assuming no elements have changed [6]. According to Crowther, a reliable survey is one that gives consistent results repeatedly, even if conducted with different samples or by different researchers.

In this study, the reliability test was carried out using the statistical instrument Cronbach's alpha on the IBM SPSS 25. Cronbach's alpha measured reliability with a coefficient level from 0 to 1 , with a minimum coefficient of 0.7 as an indicator of an acceptable level of reliability [2]. From the analysis conducted with IBM SPSS 25, it was found that the survey conducted had good internal consistency and it could be concluded that the survey was reliable.

Table 1.1 Reliability Testing Results

\begin{tabular}{cccc}
\hline No & Variable & Items & Cronbach's alpha \\
\hline 1 & Social Media Usage & 13 & 0.878 \\
2 & Suitability & 3 & 0.818 \\
3 & Cost Effectiveness & 3 & 0.747 \\
4 & Trust & 3 & 0.838 \\
5 & Interactivity & 3 & 0.890 \\
6 & Top Management Support & 4 & 0.850 \\
7 & Entrepreneurial Orientation & 7 & 0.904 \\
8 & Institutional Pressure & 6 & 0.810 \\
\hline Source: Data processed using SPSS 25 & &
\end{tabular}

\subsection{Multiple Linear Regression}

According the coefficient of determination (R) test is used to measure how far the regression model explains the variation of the independent variables. From the analysis, it is known that the value of $\mathrm{R}$ square is 0.462 . These results indicate that the use of social media in SMEs is influenced by $46.2 \%$ by variables in the context of the TOE Framework proposed in the analysis. While the remaining $53.8 \%$ is influenced by other variables outside the analysis.

Table 1.2 R-Squared Testing

\begin{tabular}{lcccc}
\hline \multicolumn{4}{c}{ Model Summary } \\
\hline Model & $\mathrm{R}$ & R Square & $\begin{array}{c}\text { Adjusted R } \\
\text { Square }\end{array}$ & $\begin{array}{c}\text { Std. Error of the } \\
\text { Estimate }\end{array}$ \\
\hline 1 & $.680^{\mathrm{a}}$ & .462 & .421 & 4.40651 \\
\hline a. Predictors: (Constant), Institutional Pressure, Trust, Top Management \\
Support, Cost Effectiveness, Entrepreneurial Orientation, Interactivity, \\
Suitability
\end{tabular}

\subsection{Analysis of Variance (F-Tests)}

According The $\mathrm{F}$ statistical test basically shows whether all the independent variables included in the model have a joint effect on the dependent variable [7]. One of the basic for making $\mathrm{F}$ test decisions is to observe the significance value. If the significance value is below 0.05 , it can be interpreted that together the independent variables have an effect on the dependent variable. From the analysis, it is known that the calculated $\mathrm{F}$ value is 11.296 and the significance value is 0.0. it can be concluded that together or simultaneously, the factors in the context of the TOE Framework affect the use of social media in MSMEs [7]. 
Table 1.3 F-Tests

\begin{tabular}{|c|c|c|c|c|c|c|}
\hline \multicolumn{7}{|c|}{ ANOVA $^{a}$} \\
\hline \multicolumn{2}{|c|}{ Model } & \multirow{2}{*}{$\begin{array}{r}\text { Sum of Squares } \\
1535.317\end{array}$} & df & Mean Square & $\mathrm{F}$ & \multirow{2}{*}{$\frac{\text { Sig. }}{.000^{\mathrm{b}}}$} \\
\hline & Regression & & 7 & 219.331 & 11.296 & \\
\hline \multirow[t]{2}{*}{1} & Residual & 1786.393 & 92 & 19.417 & & \\
\hline & Total & 3321.710 & 99 & & & \\
\hline \multicolumn{7}{|c|}{ a. Dependent Variable: Use Social Media } \\
\hline \multicolumn{7}{|c|}{$\begin{array}{l}\text { b. Predictors: (Constant), Institutional Pressure, Trust, Top Management Support, Cost Effectiveness, } \\
\text { Entrepreneurial Orientation, Interactivity, Suitability }\end{array}$} \\
\hline
\end{tabular}

\subsection{HYPOTHESES TESTING RESULTS}

The suitability of social media with technology or values contained in an MSME has a significant effect on the use of social media. From the analysis conducted, it is known that the $\mathrm{T}$ count is 2,338 or $>\mathrm{T}$ table $(\mathrm{T}$-table $\mathrm{df} 92=1.661)$ and the significance value of the suitability variable is 0.022 or $<0.05$. These results indicate H1 is accepted. These results are consistent with research conducted [2] which concludes that there is a significant influence between the suitability factor for the use of social media on MSMEs in Oman. The magnitude of the influence of the suitability factor may be caused by the compatibility of social media with various kinds of technological infrastructure that MSMEs already have.

The cost-effectiveness of social media has a significant effect on the use of social media. From the results of the analysis, it is known that the calculated $\mathrm{T}$ value of this variable is 0.512 or $<\mathrm{T}$ table (1.661) and the significance level of the cost-effectiveness variable is 0.610 or $>0.05$. These results indicate $\mathrm{H} 2$ is rejected. These results are consistent with the results of research conducted which concludes that cost effectiveness has no significant effect on the use of social media.

Trust in social media significantly influences the use of social media. From the analysis carried out, it is known that the calculated $\mathrm{T}$ value is 0.141 or $<\mathrm{T}$ Table (1.661) and the significance of the confidence variable is 0.888 or $>0.05$. These results indicate that $\mathrm{H} 4$ is rejected. These results are consistent with research conducted which concluded that the trust factor had no significant effect on the use of Facebook social media on MSMEs in Malaysia [8].

Social media interactivity significantly affects the use of social media. From the analysis, it is known that the calculated $\mathrm{T}$ value is 2.724 or $>\mathrm{T}$ Table (1.661) and the significance value of the interactivity variable is 0.008 or $<0.05$. These results indicate that H5 is accepted. These results are consistent with research conducted [5], which concludes that interactivity has a significant effect on the use of social media. These results indicate that MSMEs are concerned with interactive features of social media that can be used for their business. As is known, social media provides quite complete features for promotion, customer relations, as well as marketing and customer research.

Top management support has a significant effect on the use of social media in MSME businesses. From the analysis conducted, it is known that the calculated $\mathrm{T}$ value is 0.281 or $<\mathrm{T}$ table (1.661) and the significance of the management support variable is 0.779 or $>0.05$ which indicates that H6 is rejected. These results are consistent with research conducted on MSMEs which concludes that top management involvement is not a factor that has a significant effect on the use of social media [2]. These results imply that management does not provide significant support for the use of social media in MSMEs. 
This can be caused by the possibility that management does not consider the use of social media as a strategic need that needs attention. In addition, this may also be related to the cost factor.

The entrepreneurial orientation of the company has a significant effect on the use of social media. From the analysis conducted, it is known that the calculated T value is 2.208 or $>\mathrm{T}$ Table (1.661) and the significance of the entrepreneurial orientation variable is 0.030 or $<0.05$ which indicates that $\mathrm{H} 6$ is accepted. These results are consistent with the results of research conducted which concludes that there is a positive relationship from the entrepreneurial orientation of SMEs to the interest in adopting the use of e-commerce technology. These results indicate that the higher the entrepreneurial orientation, the higher the level of use of social media in MSMEs.

Institutional pressure significantly affects the use of social media. From the analysis, it is known that the calculated $\mathrm{T}$ value is -1.179 or $<\mathrm{T}$ table (1.661) and the significance value of the institutional pressure variable is 0.241 or $>0.05$ which indicates $\mathrm{H} 7$ is rejected. These results are consistent with research conducted by Bharati, Zhang and Chaudhury (2013) which found that institutional pressure did not have a direct effect on social media assimilation in companies. concluded that the pressure received by MSMEs from competitors and industry did not significantly affect the use of social media on MSMEs in Oman. These results indicate that there is no significant influence received by MSMEs from the environmental context. This may happen because the use of social media is relatively easy and fits the business model run by MSMEs, and a high entrepreneurial orientation makes MSMEs take the initiative themselves to use social media, so that the influence received from competitors, customers and suppliers does not have a significant impact.

\section{Conclusion}

Of the 100 MSMEs sampled in the study, it is known that most MSMEs use more than one type of social media. The purpose of using social media in MSMEs can be summarized into three aspects, namely for marketing purposes (advertising, promotion, branding), customer relations, and to seek information (research) both information about customers and competitors.

From the quantitative analysis conducted on 100 samples using multiple linear regression techniques, it is known simultaneously that the factors in the context of the TOE Framework have a significant effect on the use of social media in MSMEs. In the context of technology, the factors that have a significant effect on the use of social media are the interactivity of social media and the suitability of the technology that has been previously owned. Meanwhile, in the organizational context, the factor that has a significant effect on the use of social media in MSMEs is the business orientation of MSMEs. In the environmental context, institutional pressure is known to have no significant effect on the use of social media.

\section{References}

[1] Kemp, Simon. (2019). Digital 2019: Indonesia, All the data and trends you need to understand, Internet, social media, mobile and e-commerce behaviours in 2019. [Online] Available at https://datareportal.com/reports/digital-2019-indonesia

[2] Al Rahbi, Hafedh. S.A (2017). Factors Influencing Social Media Adoption in Small and Medium Enterprises. Thesis (Not Published) . Doctor Of Philosophy. Department Of Computer Science. Brunel University. London

[3] Oliveira, T. and Martins, M.F. (2011) Literature review of information technology adoption models at firm level, The Electronic Journal Information Systems Evaluation, 14(1), pp. 110-121. 
[4] Chatterje, S. and Hadi, A.S. (2015) Regression analysis by example. New York: John Wiley \& Sons

[5] Parveen, Farzana. 2014. Social Media Usage and Its Usage On Malaysian Organizations. Thesis (Not published). Doctor Of Philosophy Faculty Business and Accountancy. University Of Malaya. Kuala Lumpur

[6] Roberts, Paula \& Priest, Helena \& Traynor, Michael. (2006). "Reliability and validity in research". Nursing Standard. Vol 20. pp41-45. 10.7748/ns.20.44.41.s56.

[7] Ghozali, Imam. 2016. Aplikasi analisis multivarianate dengan program IBM SPSS 21. Semarang: Universitas Diponegoro

[8] Ainin, S., Parveen, F., Moghavvemi, S., Jaafar, N. and Mohd Shuib, N. (2015), "Factors influencing the use of social media by SMEs and its performance outcomes", Industrial Management \& Data Systems, Vol. 115 No. 3, pp. 570-588. 